\title{
Treatment of Tobacco Use in Preconception Care
}

\author{
Abby C. Rosenthal - Cathy L. Melvin . \\ Dianne C. Barker
}

Published online: 1 August 2006

(C) Springer Science+Business Media, Inc. 2006

Keywords $\cdot$ Smoking $\cdot$ Pregnancy $\cdot$ Preconception care

The preconceptional period provides an important opportunity to actively assess and treat tobacco use and to assist parents-to-be in quitting permanently to avoid smokingrelated pregnancy and long-term health consequences.

The use of tobacco prior to conception is associated with male impotence, conception delay, and primary as well as secondary infertility. During pregnancy, tobacco use increases the risk for spontaneous abortion, ectopic pregnancy, low birth weight, SIDS, premature birth, and other fetal and maternal complications [1]. Each year, almost one-half million babies in the United States are born to mothers who report smoking during pregnancy [2]. For smokers, tobacco use continues to be the leading cause of morbidity and mortality in the United States, resulting in approximately 440,000 deaths per year [3].

Women smokers are at increased risk for cancer, cardiovascular disease, and pulmonary disease. Since 1987, lung cancer has outpaced breast cancer as the leading cause of cancer death among women, and exposure to environmental tobacco smoke (ETS) is a cause of lung cancer and

A. C. Rosenthal

Office on Smoking and Health, Centers for Disease Control and Prevention, Mailstop K-50,

3005 Chamblee Tucker Road, Atlanta, GA, 30341 USA

e-mail: als7@cdc.gov

C. L. Melvin $(\square)$

Sheps Center for Health Services Research, University of North Carolina, 725 MLK Jr. Blvd. CB\#7590,

Chapel Hill, NC, 27599-7590 USA

D. C. Barker

Barker Bi-Coastal Health Consultants, 3556 Elm Drive, Calabasas, CA, 91302 USA coronary heart disease among lifetime nonsmokers. Moreover, infants born to women who are exposed to ETS during pregnancy may also have increased health risks, including small decrements in birth weight and slightly increased risk for intrauterine growth retardation, compared with infants born to women who were not exposed [1].

Despite all that is known about the devastating health consequences of smoking, $20 \%$ of U.S. women smoked cigarettes in 2003 [4] and $11.4 \%$ of women giving birth reported smoking during their pregnancy [5]. It is encouraging that $70 \%$ of smokers want to quit, and about two-fifths quit for at least a day every year [4]. To avoid early pregnancy complications, women who smoke should be counseled to quit before they become pregnant. In addition, smokers who are partners of mothers-to-be should also be included in any treatment plans given the strong association with partner smoking and relapse [6] as well as concerns about ETS exposure.

Treatment for tobacco dependence is safe, effective, available, and affordable [7]. The 2000 Public Health Service document, Treating Tobacco Use and Dependence: A Clinical Practice Guideline [7], as well as the 2001 Centers for Disease Control and Prevention publication, Guide to Cоттиnity Preventive Services [8], both provide strong evidencebased guidelines for treating smokers using a comprehensive system that includes the 5A's (a brief 5-step counseling approach recommended by the 2000 PHS clinical practice guideline for all smokers). These documents also provide details of how reminder systems, telephone quitlines, decreased co-pays and costs of treatment, mass media campaigns, smoke free environments and increased prices for tobacco products support the cessation process $[7,8]$.

At the clinical level, every clinician providing preconception care should implement a tobacco treatment system based on the $5 \mathrm{~A}$ 's and beginning with a systematic way to assess 
tobacco use. This evidence-based counseling approach includes asking every patient about tobacco use and, if they smoke, advising them to quit, assessing willingness to quit, assisting them in quitting, and arranging follow-up. Assisting may include the offer of pharmacotherapies or additional counseling, each of which doubles the quit rates in nonpregnant adult populations [7]. The effectiveness of counseling increases as the intensity (number and length of sessions) increases. At present, seven first-line FDA-approved medications are available: bupropion varenicline and five nicotine replacement therapies (gum, patch, lozenge, inhaler, and nasal spray) [7]. Because the safety and efficacy of pharmacotherapy during pregnancy has yet to be established, the preconception period provides an excellent interval before pregnancy to offer these effective adjuncts to quitting.

Once abstinent, patients should be followed to help avoid relapse. For those smokers who are not willing to quit in the near future, the PHS clinical practice guidelines recommend the 5 R's (relevance, risks, rewards, roadblocks, repetition) to enhance patients' motivation to quit smoking [7].

Clinical systems that provide tobacco-dependence treatment should also include a reminder system to alert providers to advise smokers in their practice [8]. This system might be an electronic medical record alert or simply a stamp or sticker on the patient's chart to indicate tobacco status - current, former, or never. The PHS guideline also recommends using the 305.1 ICD-10 code for tobacco dependence for billing purposes [7]. This code also may be used by health-care systems to monitor and improve the provision of effective treatment.

State quitlines provide an effective vehicle for telephone counseling and can be accessed by calling 1-800-QUIT NOW, a national portal number to refer tobacco users directly to their state quit line based on their area code. A small number of states also provide over-the-counter medications to eligible populations in conjunction with telephone counseling. Another group of states (e.g., Maine, Massachusetts, Oklahoma, Oregon, and Wisconsin) encourages providers to fax referrals (with patient consent) to the state quitline, which in turn proactively calls the smoker to begin counseling. Most quitlines send a "quit kit" to each caller.

With effective treatment, quit rates can be as high as $25 \%-30 \%$ in the general population [9]. Because many women spontaneously quit upon learning about their pregnancy-ranging from $11 \%$ to $28 \%$ in publicly insured pregnant smokers to $40 \%$ to $65 \%$ in privately insured pregnant smokers [10], it is reasonable to expect that effective preconception tobacco-dependence treatment could exceed these rates, particularly if partners who smoke are treated as well. Placing these cost-effective treatment systems into preconception practice should not be insurmountable, given the evidence, the affordability, the lessons learned from other clinical tobacco-dependence systems, and the availability of resources.
Available Resources for learning more about tobacco dependence treatment:

- Treating Tobacco Use and Dependence. JAMA June, 28, 2000 (Summary article)

- Treating Tobacco Use and Dependence (full document). Available at www.surgeongeneral.gov/tobacco.

- Agency for Health Care Research and Quality, patient and provider materials. Available at www.ahrq.gov.

- The Guide to Community Preventive Services. Available at www.thecommunityguide.org .

- Telephone Quitlines: A Resource for Development, Implementation, and Evaluation. Available at www.cdc.gov/tobacco.

- Smoke-Free Families provider, patient, and system materials. Available at www.smokefreefamilies.org.

- Environmental Protection Agency, smokefree home ban materials. Available at www.epa.gov .

- March of Dimes at www.marchofdimes.com.

- Nicotine and Tobacco Research Journal supplement: Helping Pregnant Women Quit Smoking: Progress and Future Directions. Available at http://www.ntrjournal.org/pregnancy.html.

\section{References}

1. U.S. Department of Health and Human Services. Health consequences of tobacco use among women. In Women and Smoking: A Report of the Surgeon General. (177-450). Rockville, MD: Centers for Disease Control and Prevention, National Center for Health Statistics; 2001.

2. Martin JA, Hamilton BE, Sutton PD, Ventura SJ, Menacker F, Munson ML. Births: final data for 2002. Nati Vital Stat Rep 2003;52:12.

3. Centers for Disease Control and Prevention. Annual SmokingAttributable Mortality, Years of Potential Life Lost, and Productivity Losses-United States, 1997-001. Morb Mortal Wkly Rep 2005;54;625-8.

4. Centers for Disease Control and Prevention. Cigarette Smoking Among Adults,-United States, 2003. Morb Mortal Wkly Rep 2005;54:509-13.

5. Centers for Disease Control and Prevention. Cigarette Smoking During Pregnancy-United States, 1990-2002. Morb Mortal Wkly Rep 2004;53:911-5.

6. Mullen PD. How can more smoking suspension during pregnancy become life long abstinence? Lessons learned about predictors, interventions, and gaps in our accumulated knowledge. Nicotine Tob Res 2004;6(Suppl. 2):S217-S238.

7. Fiore MC, Bailey WC, Cohen SJ, et al. A Clinical Practice Guideline for Treating Tobacco Use and Dependence. Rockville, MD: US Department of Health and Human Services, Public Health Service; 2000.

8. Hopkins DP, Briss PA, Ricard CJ, et al. Task Force on Community Preventive Services. Am J Prev Med 2001;20(2 Suppl):16-66.

9. Centers for Disease Control and Prevention. Telephone Quitlines: A Resource for Development, Implementation, and Evaluation. Atlanta: CDC; 2004.

10. Melvin CL, Gaffney CA. Treating nicotine use and dependence of pregnant and parenting smokers: an update. Nicotine Tob Res 2004;6(Suppl. 2):S112. 